Check for updates

Cite this: RSC Adv., 2017, 7, 31372

\title{
Isotope selective activation: a new insight into the catalytic activity of urease
}

\author{
Sanchi Maithani, $\uparrow^{\mathrm{a}}$ Mithun Pal, $\uparrow^{\mathrm{a}}$ Abhijit Maity ${ }^{\mathrm{a}}$ and Manik Pradhan (D) *ab
}

Urease, a metalloenzyme, requires carbon dioxide $\left(\mathrm{CO}_{2}\right)$ for its activation. But, whether this activation is isotope-specific to ${ }^{12} \mathrm{CO}_{2}$ or ${ }^{13} \mathrm{CO}_{2}$, is not yet known and even the potential role of $\mathrm{CO}_{2}$ in the enzymatic activity of urease is poorly understood. Here, we provide direct experimental evidence that the catalytic activity of urease exhibits a unique isotope-specific response where the ${ }^{12} \mathrm{CO}_{2}$ isotope is strongly preferred over the ${ }^{13} \mathrm{CO}_{2}$ isotope during its catalytic activation. Moreover, this isotope-selective activation depends on different isotopic fractionations $\left({ }^{12} \mathrm{C}:{ }^{13} \mathrm{C}\right)$ of the reaction-environment as well as the substrate urea $\left({ }^{13} \mathrm{C}\right.$-urea and ${ }^{12} \mathrm{C}$-urea), where the ${ }^{12} \mathrm{CO}_{2}$ isotope in the reaction medium essentially facilitates the hydrolysis of ${ }^{13} \mathrm{C}$-enriched urea. This deepens our understanding of the isotope-specific urease activation and its potential role in hydrolytic reaction. Our findings thus may offer novel opportunities for a better fundamental understanding of isotope-specificity in chemical reactions involving metalloenzymes.

Received 15th May 2017

Accepted 14th June 2017

DOI: $10.1039 / \mathrm{c} 7 \mathrm{ra05489k}$

rsc.li/rsc-advances reaction kinetics, ${ }^{8}$ action of buffers ${ }^{9}$ and effect of temperature. ${ }^{\mathbf{1 0}}$ But the mechanism underlying the activation of urease or its potential role in hydrolytic reaction still remains controversial. Moreover, it was demonstrated in the past that the metalloenzyme urease requires $\mathrm{CO}_{2}$ for its activation. ${ }^{11,12}$ Therefore, the product of the urease-catalyzed hydrolysis of urea and the activator of the catalyst (i.e. $\mathrm{CO}_{2}$ ) being the same entity makes the reaction mechanism more complex. In this context, the detailed study of isotopic signatures of $\mathrm{CO}_{2}$ (i.e. ${ }^{13} \mathrm{CO}_{2}$ and ${ }^{12} \mathrm{CO}_{2}$ ) would provide better insight into the reaction mechanisms. However, so far there have been no studies focused on the potential role of isotope-specific $\mathrm{CO}_{2}$ environment on the isotopic-fractionations of in situ $\mathrm{CO}_{2}$ production in the ureaseurea reaction. Moreover, how the variation of isotopic compositions $\left({ }^{12} \mathrm{C}:{ }^{13} \mathrm{C}\right)$ of the substrate urea $\left({ }^{13} \mathrm{C}\right.$-urea and ${ }^{12} \mathrm{C}$-urea $)$ affects the catalytic activity of urease particularly in the environment of atmospheric $\mathrm{CO}_{2}$ concentration, has never been explored and therefore remains an open question. Consequently, unravelling the reaction mechanism involving the isotope-selective activation of urease would open new perspectives for a better understanding of the role of $\mathrm{CO}_{2}$ for urease activation kinetics.

In this study, we report for the first time, that the enzymatic activity of urease exhibits a unique isotope-selective $\mathrm{CO}_{2}$ affinity. Furthermore, we have showed that the catalytic activity of urease depends on the isotopic compositions of both reaction-environment and substrate. Finally, we also demonstrate that the isotope-specific activation of urease is bufferindependent. This new knowledge is of great significance for fundamental understanding of isotope-specific chemical reactions involving metalloenzymes. Fig. 1 illustrates a scheme
${ }^{a}$ Department of Chemical, Biological and Macromolecular Sciences, S. N. Bose National Centre for Basic Sciences, Salt Lake, JD Block, Sector III, Kolkata-700098, India. E-mail: manik.pradhan@bose.res.in; manik.pradhan@gmail.com; Fax: +91 332335 3477; Tel: +91332335 5706; +913323355708

${ }^{b}$ Technical Research Centre (TRC), S. N. Bose National Centre for Basic Sciences, Salt Lake, JD Block, Sector III, Kolkata-700098, India

$\dagger$ Both authors contributed equally to this work and should be considered as joint first authors. 


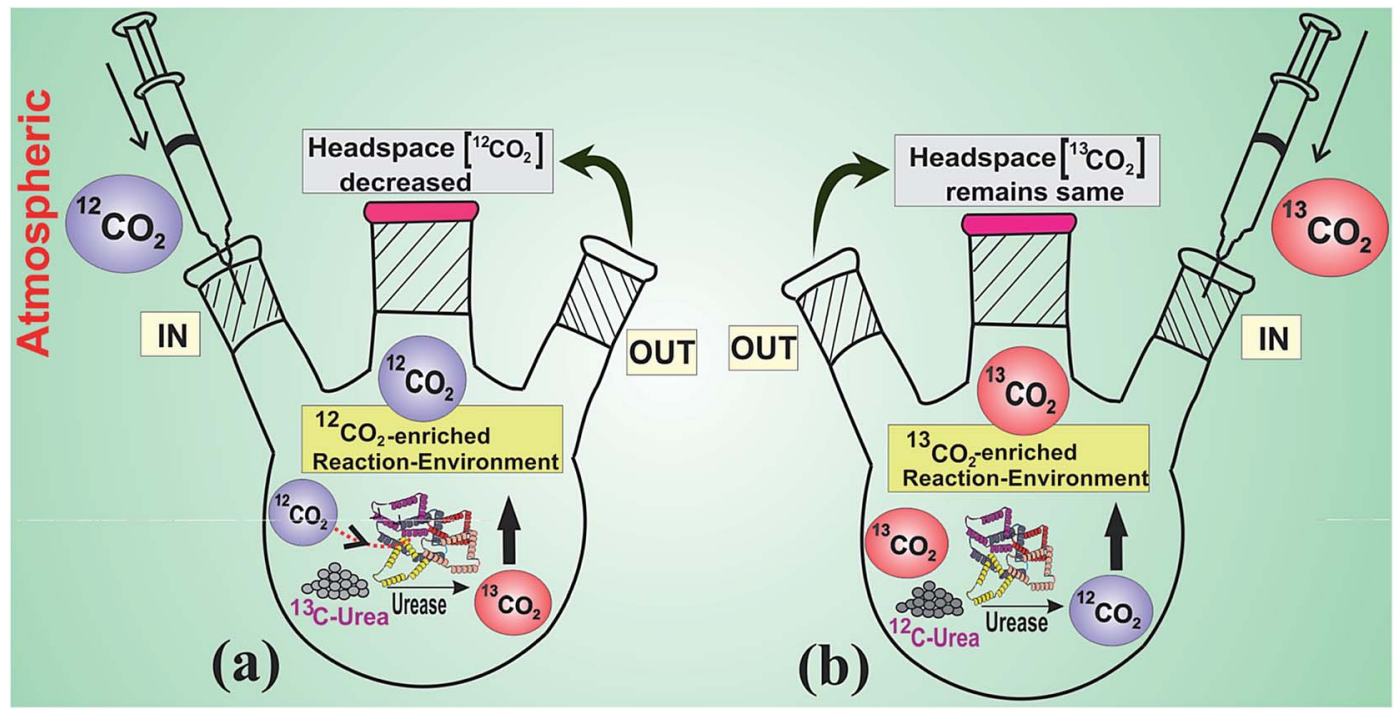

Fig. 1 A scheme showing the isotope-specific catalytic reaction of urease enzyme. (a) Isotopic ${ }^{12} \mathrm{CO}_{2}$ concentration deceases with simultaneous in situ generation of ${ }^{13} \mathrm{CO}_{2}$ isotope in the urease-catalyzed hydrolysis of ${ }^{13} \mathrm{C}$-urea, (b) urease specifically requires ${ }^{12} \mathrm{CO}_{2}$, exhibiting no intake of ${ }^{13} \mathrm{CO}_{2}$ even in an enriched ${ }^{13} \mathrm{CO}_{2}$ reaction-environment.

showing the isotope-specificity of urease enzyme and specific requirement of ${ }^{12} \mathrm{CO}_{2}$ isotope for its activation.

\section{Result and discussion}

To investigate the urease $(1 \mu \mathrm{M})$-catalyzed hydrolysis of isotope enriched ${ }^{12} \mathrm{C}$ and ${ }^{13} \mathrm{C}$-urea $(4 \mathrm{mM})$ at different reaction environments, we first altered the headspace of the reaction with increasing concentration of ${ }^{12} \mathrm{CO}_{2}$ (with $\sim 1.1 \%$ natural abundance of ${ }^{13} \mathrm{CO}_{2}$ ) starting from $\mathrm{CO}_{2}$-free pure $\mathrm{N}_{2}$ environment. It is noteworthy to mention here that only the concentration of ${ }^{12} \mathrm{CO}_{2}$ or ${ }^{13} \mathrm{CO}_{2}$ isotopes is regulated keeping the total pressure constant at around atmospheric pressure above the reaction medium. We observed (Fig. 2a) that the headspace ${ }^{12} \mathrm{CO}_{2}$ concentration was absorbed with simultaneous in situ generation of ${ }^{13} \mathrm{CO}_{2}$ in the urease-catalyzed hydrolysis of ${ }^{13} \mathrm{C}$ urea. We also interestingly (Fig. 2a) observed that while ${ }^{13} \mathrm{C}-$ urea derived in situ ${ }^{13} \mathrm{CO}_{2}$ production is increased gradually with increasing initial headspace concentration of ${ }^{12} \mathrm{CO}_{2}$, at the same time the final headspace ${ }^{12} \mathrm{CO}_{2}$ concentration is decreased more in the reaction. Taken together, these observations indicate that there is a potential link between the enzymatic activity of urease and the requirement of specific isotope of $\mathrm{CO}_{2}$ (i.e. ${ }^{12} \mathrm{CO}_{2}$ ). These observations are indistinguishable for ureasecatalyzed hydrolysis of ${ }^{12} \mathrm{C}$-urea because the product and the headspace component are the same isotopic species $\left(\right.$ i.e. $\left.{ }^{12} \mathrm{CO}_{2}\right)$.

Another striking finding revealed in our observations (Fig. 2b) is that in $\mathrm{CO}_{2}$-free pure $\mathrm{N}_{2}$ environment, the in situ generation of ${ }^{13} \mathrm{CO}_{2}$ concentration from ${ }^{13} \mathrm{C}$-urea was observed to be the lowest value, whereas the ${ }^{12} \mathrm{C}$-urea derived in situ
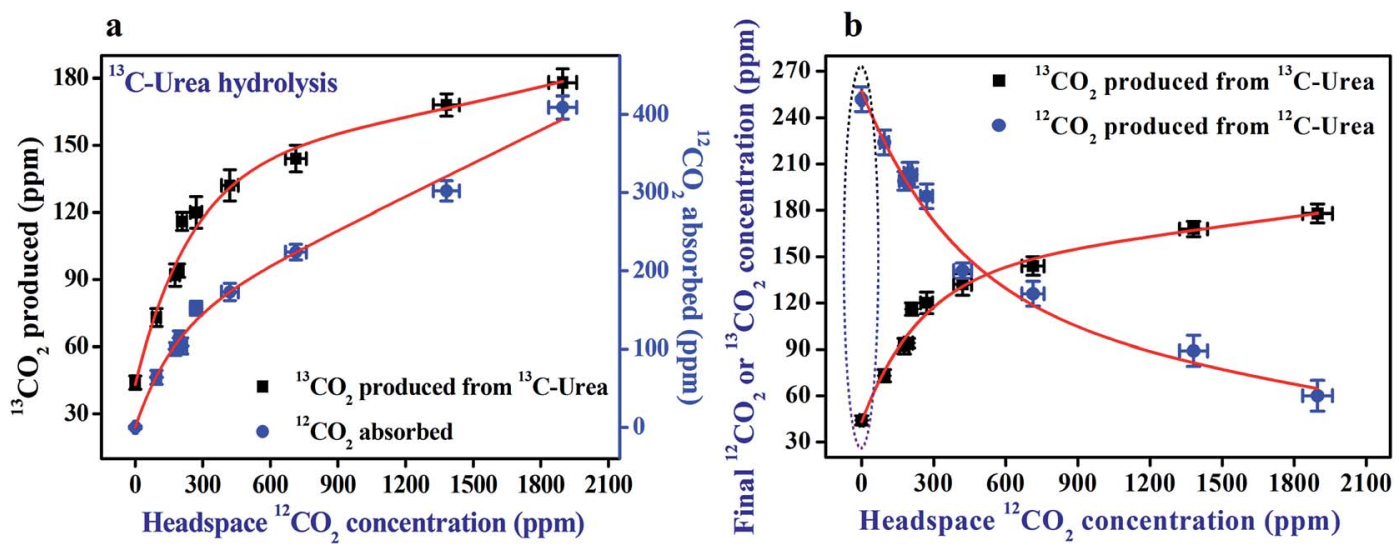

Fig. 2 Urease $(1 \mu \mathrm{M})$-catalysed hydrolysis of $(4 \mathrm{mM}){ }^{13} \mathrm{C}$-urea $\left(\geq 99 \%{ }^{13} \mathrm{C}\right)$ and ${ }^{12} \mathrm{C}$-urea $\left(\geq 99 \%{ }^{12} \mathrm{C}\right)$ at different headspace concentrations (partial pressures) of ${ }^{12} \mathrm{CO}_{2}$. (a) ${ }^{13} \mathrm{CO}_{2}$ is generated while headspace ${ }^{12} \mathrm{CO}_{2}$ concentration has been absorbed in the hydrolysis of ${ }^{13} \mathrm{C}$ - urea. (b) ${ }^{13} \mathrm{C}-\mathrm{Urea}$ derived ${ }^{13} \mathrm{CO}_{2}$ has been increased whereas ${ }^{12} \mathrm{C}$-urea derived ${ }^{12} \mathrm{CO}_{2}$ has been diminished with increasing headspace ${ }^{12} \mathrm{CO}_{2} \mathrm{concentration}$. The dotted region shows the $\mathrm{CO}_{2}$-free pure $\mathrm{N}_{2}$ headspace condition. 

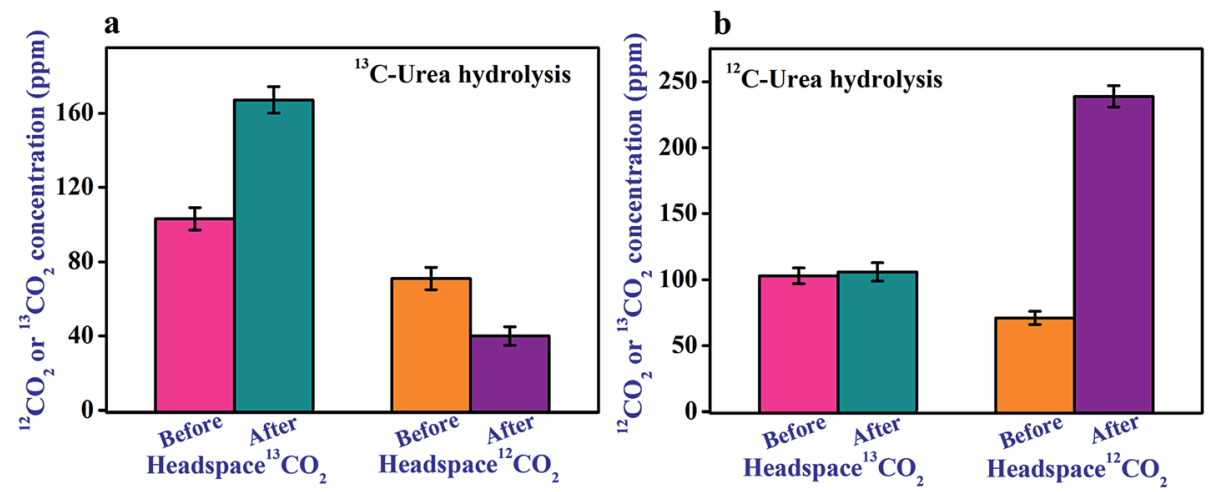

Fig. 3 Urease $(1 \mu \mathrm{M})$-catalysed hydrolysis of $(4 \mathrm{mM}){ }^{13} \mathrm{C}$-urea $\left(\geq 99 \%{ }^{13} \mathrm{C}\right)$ and ${ }^{12} \mathrm{C}$-urea $\left(\geq 99 \%{ }^{12} \mathrm{C}\right)$ at enriched headspace concentrations (partial pressures) of ${ }^{13} \mathrm{CO}_{2}\left({ }^{12} \mathrm{CO}_{2}:{ }^{13} \mathrm{CO}_{2}: 40 \%: 60 \%\right.$ ). (a and b) Depict the variation of ${ }^{13} \mathrm{CO}_{2}$ and ${ }^{12} \mathrm{CO}_{2}$ concentrations before and after the reaction of urease-catalysed hydrolysis of ${ }^{13} \mathrm{C}$-urea and ${ }^{12} \mathrm{C}$-urea, respectively.

production of ${ }^{12} \mathrm{CO}_{2}$ concentration was found to be markedly enhanced. However, in absence of any ${ }^{12} \mathrm{CO}_{2}$, the catalytic activity of urease diminishes and subsequently the hydrolysis of ${ }^{13} \mathrm{C}$-urea becomes very small, resulting in lower amount of ${ }^{13} \mathrm{CO}_{2}$ production. In contrast, ${ }^{12} \mathrm{C}$-urea derived in situ ${ }^{12} \mathrm{CO}_{2}$ itself facilitates the enzymatic activity of urease and thus ureasecatalyzed hydrolysis of ${ }^{12} \mathrm{C}$-urea is not hindered in $\mathrm{CO}_{2}$-free pure $\mathrm{N}_{2}$ environment. However, ${ }^{12} \mathrm{C}$-urea derived in situ production of ${ }^{12} \mathrm{CO}_{2}$ decreases with increase of initial headspace concentration of ${ }^{12} \mathrm{CO}_{2}$ and this is likely to be the combined effect of partial pressure of the same species ${ }^{12} \mathrm{CO}_{2}$ above the reaction medium as well as the over-saturation of urease enzyme in presence of excess headspace ${ }^{12} \mathrm{CO}_{2}$.

We next altered the headspace environment with $\sim 60 \%(103$ $\mathrm{ppm}$ ) isotope enriched ${ }^{13} \mathrm{CO}_{2}$ (of $174 \mathrm{ppm}$ total $\mathrm{CO}_{2}$ ), (instead of $\sim 1.1 \%$ natural abundance as in the previous case), to ensure the specific role of ${ }^{12} \mathrm{CO}_{2}$ in the catalytic activity of urease. We found (Fig. 3a) that initial headspace ${ }^{13} \mathrm{CO}_{2}$ concentration was not absorbed at all, while the headspace ${ }^{12} \mathrm{CO}_{2}$ was markedly decreased in the usual way for urease $(1 \mu \mathrm{M})$-catalyzed hydrolysis of $(4 \mathrm{mM}){ }^{13} \mathrm{C}$-urea. Moreover, under this altered environmental conditions in headspace, no noticeable effect of enriched headspace ${ }^{13} \mathrm{CO}_{2}$ concentration was observed (Fig. 3b) even for urease $(1 \mu \mathrm{M})$-catalyzed hydrolysis of $(4 \mathrm{mM}){ }^{12} \mathrm{C}$-urea. Our observation clearly manifests that urease preferentially links to ${ }^{12} \mathrm{CO}_{2}$ for its activation, thus unveiling a missing link between the enzymatic activity of urease and the necessity for ${ }^{12} \mathrm{CO}_{2}$ isotope.

Next, we examined the catalytic activity of urease in response to the different isotopic-compositions $\left({ }^{12} \mathrm{C}:{ }^{13} \mathrm{C}\right)$ of the substrate urea to gain a better insight into the fundamental processes of isotope - selective nature of urease with a fixed headspace atmospheric $\mathrm{CO}_{2}$ concentration $(\sim 360 \mathrm{ppm})$. The different isotopic-compositions $\left({ }^{12} \mathrm{C}:{ }^{13} \mathrm{C}\right)$ were achieved by suitably mixing ${ }^{12} \mathrm{C}$-urea and ${ }^{13} \mathrm{C}$-urea, while retaining the same concentration of urea $(4 \mathrm{mM})$. We observed (Fig. $4 \mathrm{a})$ that the in situ generation of the product ${ }^{13} \mathrm{CO}_{2}$ from hydrolysis of $1: 2$ $\left({ }^{12} \mathrm{C}:{ }^{13} \mathrm{C}\right)$ isotopic-composition of urea was almost identical to that of $1: 99\left({ }^{12} \mathrm{C}:{ }^{13} \mathrm{C}\right)$ isotopic-composition. However, ${ }^{13} \mathrm{C}-$ isotopic enrichment of the substrate urea for $1: 2\left({ }^{12} \mathrm{C}:{ }^{13} \mathrm{C}\right)$ isotopic-composition was significantly lower than that of $1: 99$ $\left({ }^{12} \mathrm{C}:{ }^{13} \mathrm{C}\right)$ isotopic-compositions. This observation demonstrates that the in situ availability of ${ }^{12} \mathrm{CO}_{2}$ derived from the ${ }^{12} \mathrm{C}$ urea, itself activates urease for higher hydrolysis of ${ }^{13} \mathrm{C}$-fraction of the $1: 2\left({ }^{12} \mathrm{C}:{ }^{13} \mathrm{C}\right)$ isotopic-composition of urea, whereas the

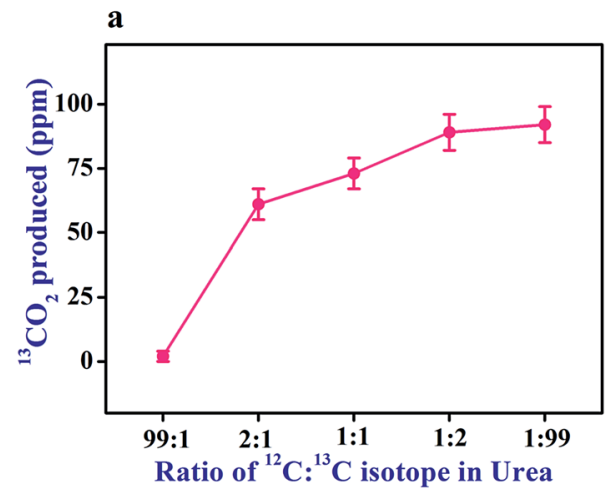

b

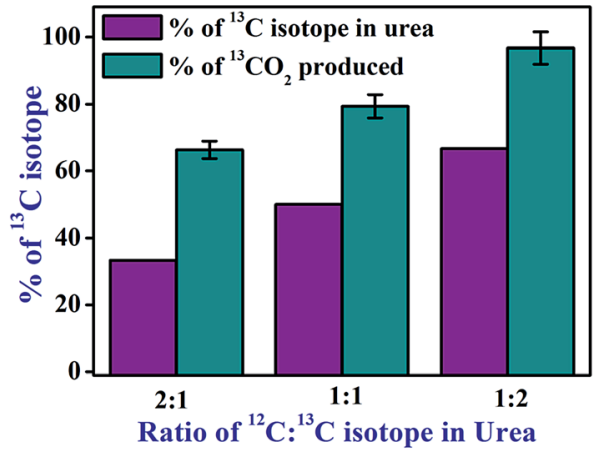

Fig. 4 Urease $(1 \mu \mathrm{M})$-catalysed hydrolysis of $(4 \mathrm{mM})$ different isotopic compositions $\left({ }^{12} \mathrm{C}:{ }^{13} \mathrm{C}\right)$ of substrate urea at a fixed head-space concentration of $\mathrm{CO}_{2}(\sim 360 \mathrm{ppm})$. (a) Demonstrates the ${ }^{13} \mathrm{CO}_{2}$ evolved in the hydrolysis of $(4 \mathrm{mM})$ different isotopic compositions $\left({ }^{12} \mathrm{C}:{ }^{13} \mathrm{C}\right)$ of urea. (b) Depicts a comparison between \% content of ${ }^{13} \mathrm{C}$ isotope in urea and ${ }^{13} \mathrm{CO}_{2}$ produced in the reaction with urease. 

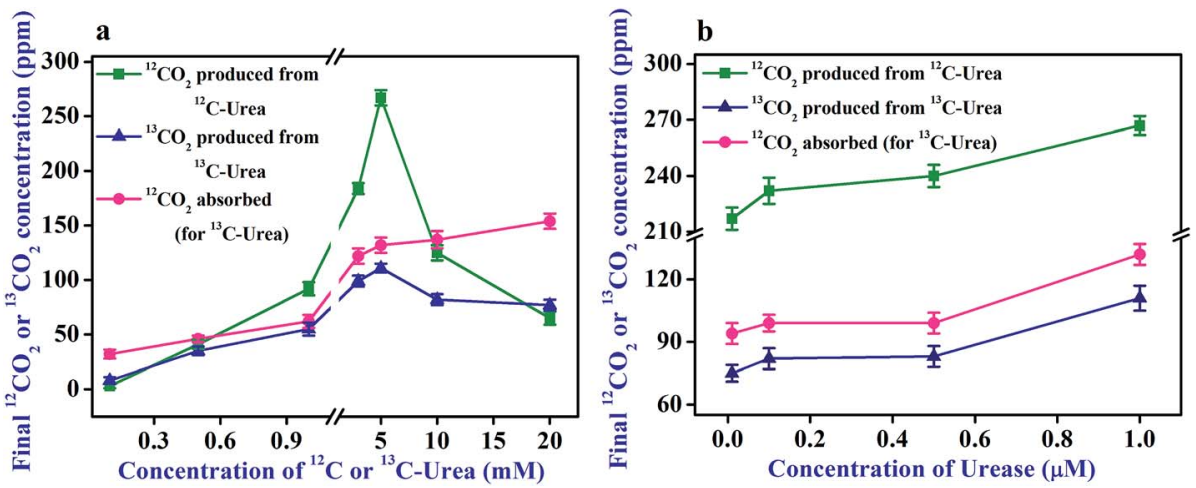

Fig. 5 Concentration dependent study of urease-catalysed hydrolysis of ${ }^{12} \mathrm{C}$-urea and ${ }^{13} \mathrm{C}$-urea. (a and b) Elucidate the effect of different concentrations of urea and urease, respectively.

${ }^{13} \mathrm{C}$-urea $\left({ }^{12} \mathrm{C}:{ }^{13} \mathrm{C}: 1: 99\right)$ was not effectively hydrolysed in absence of in situ generation of ${ }^{12} \mathrm{CO}_{2}$ in the reaction medium.

In order to gain a detailed and in-depth understanding of the role of ${ }^{12} \mathrm{CO}_{2}$ derived from different isotopic fractionations of ${ }^{12} \mathrm{C}$-urea, we then normalized the in situ generation of ${ }^{13} \mathrm{CO}_{2}$ from the different isotopic-compositions of urea (i.e. $2: 1,1: 1$ and $1: 2$ ) to the percentage (\%) of ${ }^{13} \mathrm{CO}_{2}$ produced from $99 \%$ ${ }^{13} \mathrm{C}$-urea (i.e. $1: 99$ ) and this is illustrated in Fig. $4 \mathrm{~b}$. It was found (Fig. 4b) that the percentage of in situ ${ }^{13} \mathrm{CO}_{2}$ production was much higher than the ${ }^{13} \mathrm{C}$ percentage actually present in all the different isotopic-compositions of urea, suggesting the inadequate hydrolysis of ${ }^{13} \mathrm{C}$-urea $(1: 99)$ in absence of sufficient in situ ${ }^{12} \mathrm{CO}_{2}$ concentration in the reaction medium. Therefore, urease-catalyzed hydrolysis of urea was also found to be strongly affected due to the different isotopic fractionations of substrate urea in presence of $\mathrm{CO}_{2}$ environment. Taken together, our data clearly suggest that ${ }^{12} \mathrm{CO}_{2}$ isotope plays a vital role that facilitates the enzymatic activity of urease enzyme.

The potential effect of ${ }^{12} \mathrm{C}$-urea and ${ }^{13} \mathrm{C}$-urea on the urease activation was further elucidated in response to different substrate (urea) and enzyme (urease) concentrations while maintaining the headspace at a typical atmospheric $\mathrm{CO}_{2}$

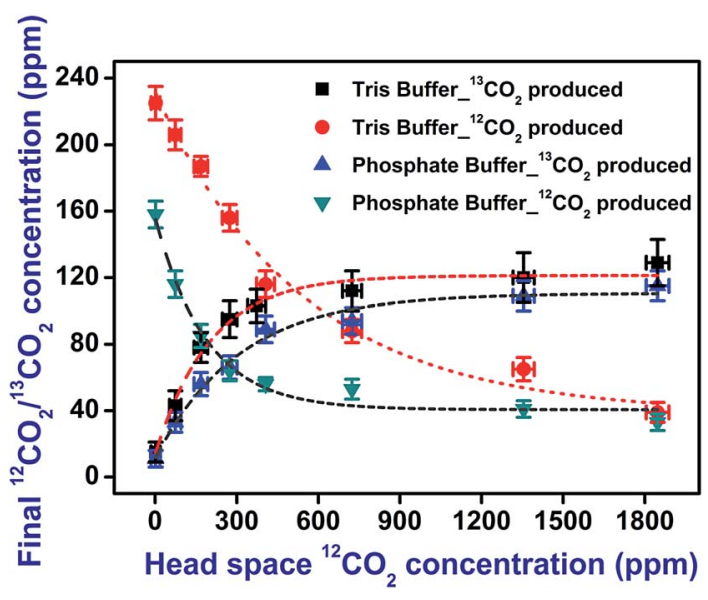

Fig. 6 The effect of buffer medium. The hydrolysis of ${ }^{12} \mathrm{C}$-urea and ${ }^{13} \mathrm{C}$-urea in ${ }^{12} \mathrm{CO}_{2}$ environment is performed in Tris buffer $(\mathrm{pH} 7.4)$ and phosphate buffer $(\mathrm{pH}$ 7). concentration $(\sim 360 \mathrm{ppm})$. The product $\left({ }^{12} \mathrm{CO}_{2}\right.$ or $\left.{ }^{13} \mathrm{CO}_{2}\right)$ of $(1 \mu \mathrm{M})$ urease-catalyzed hydrolysis of ${ }^{12} \mathrm{C}$-urea and ${ }^{13} \mathrm{C}$-urea was found (Fig. 5a) to be gradually increased with increasing concentration of urea $\left({ }^{12} \mathrm{C}\right.$-urea or ${ }^{13} \mathrm{C}$-urea) from $100 \mu \mathrm{M}$ to $5 \mathrm{mM}$. The observation was followed by a sharp decline after $5 \mathrm{mM}$ urea concentration, thus exhibiting the effect of substrate-inhibition on the urease-catalyzed hydrolysis. In contrast, keeping the urea concentration fixed ( $4 \mathrm{mM})$, there was no significant change of the concentration of the product $\left({ }^{12} \mathrm{CO}_{2}\right.$ or $\left.{ }^{13} \mathrm{CO}_{2}\right)$ with increasing concentration of urease enzyme (Fig. 5b), thus indicating that urease still hydrolyzes urea in an efficient way and thereby indicates the steady catalytic activity of urease. However, it is noteworthy that the isotope-specific activation of urease was observed throughout the study. Our findings also indicate that the lower in situ generation of ${ }^{13} \mathrm{CO}_{2}$ eventually signifies the hydrolysis of lesser amount of ${ }^{13} \mathrm{C}$-urea in absence of adequate activation of urease resulting from the headspace ${ }^{12} \mathrm{CO}_{2}$ concentration.

Finally, we investigated the isotope-specific enzymatic activity of urease in two buffer mediums (Tris-buffer and phosphate buffer) to eliminate the potential effect of $\mathrm{CO}_{2}$ on the $\mathrm{pH}$ of the reaction medium. It is worth noting that the previous experiments in the present study were carried out in a bufferfree aqueous medium to avoid the effect of urease inhibition in presence of buffer ions. ${ }^{5}$ Fig. 6 depicts that this activation in the buffer mediums is not significantly changed compared to the buffer-free system. However, the diminished magnitude of the concentration of the products, ${ }^{12} \mathrm{CO}_{2}$ and ${ }^{13} \mathrm{CO}_{2}$ observed in the buffer mediums is exhibited to be the well-known inhibitory effect of buffer ions in the reaction.

\section{Conclusion}

In conclusion, our findings provide new evidences that the catalytic activity of urease exhibits a unique isotope specific response. We have shown that the ${ }^{12} \mathrm{CO}_{2}$ isotope is strongly preferred over the ${ }^{13} \mathrm{CO}_{2}$ isotope by the urease enzyme during its catalytic activation. It was earlier reported ${ }^{\mathbf{1 1}}$ that $\mathrm{CO}_{2}$ acts as a ligand in urease-urea reaction. Hence, the isotope preferential activation of urease enzyme may be attributed to the fact that ${ }^{12} \mathrm{CO}_{2}$ isotope possibly offers lower interaction energy than ${ }^{13} \mathrm{CO}_{2}$ isotope in this ligand-enzyme interaction. However, 
quantum-mechanical simulations of interaction energy for both the isotopes would provide better insight and further exploration of the isotope specific activation of urease enzyme. We also provide direct experimental evidences that deepens our understanding of how the activation of urease depends on the isotopic compositions $\left({ }^{12} \mathrm{C}:{ }^{13} \mathrm{C}\right)$ of reaction-environment as well as the substrate urea. Despite these new evidences, however, there still remains a great deal to be explored about the underlying mechanisms linking the specific requirement of ${ }^{12} \mathrm{CO}_{2}$ isotope for the activation of urease. Moreover, new insights into the isotope-specific responses in urease-activation are fostering exploration of a new arena to study the chemical reactions involving metalloenzyme.

\section{Materials}

Jack-bean urease enzyme (E.C. 3.5.1.5) was purchased from Sigma Aldrich and ${ }^{13} \mathrm{C}$-enriched urea $\left({ }^{13} \mathrm{C}\right.$-urea, 99\%) (CCLM311-GMP) was obtained from Cambridge Isotopic Laboratories, Inc., USA. All other chemicals, including ACS grade urea with $99 \%{ }^{12} \mathrm{C}$-enrichment $\left({ }^{12} \mathrm{C}\right.$-urea $)$, were acquired from Sigma Aldrich and were used without further purification. Milli-Q water was used to prepare the aqueous solutions.

\section{Method}

The aqueous solutions of ${ }^{12} \mathrm{C}$-urea, ${ }^{13} \mathrm{C}$-urea and Jack-bean urease were utilized, unless stated otherwise, in the entire study. The reactions were carried out in sealed round-bottomed flasks wherein different concentrations of $\mathrm{CO}_{2}$ were maintained. To eliminate the interference due to air, the flasks were purged with $\mathrm{CO}_{2}$-free nitrogen before the experiments. The products $\left({ }^{12} \mathrm{CO}_{2}\right.$ or $\left.{ }^{13} \mathrm{CO}_{2}\right)$ of urease-catalyzed hydrolysis of urea ${ }^{12} \mathrm{C}$ or ${ }^{13} \mathrm{C}$-urea) were considered at the equilibrium of the reaction and the termination timing of the reaction was set to be at 60 minutes which was confirmed by Berthelot's experiment. After 60 minutes of the progress of the reaction, acidification was done using $\mathrm{H}_{3} \mathrm{PO}_{4}$ to extract the dissolved $\mathrm{CO}_{2}$ into headspace. The headspace $\mathrm{CO}_{2}$ was then collected from each flask and measured by a high-precision laser-based Integrated Cavity Output Spectroscopy (ICOS) technique. The net isotopic concentrations of $\mathrm{CO}_{2}$ produced from the hydrolysis reactions were calculated after subtracting the same from a blank flask containing only urease at equal initial $\mathrm{CO}_{2}$ concentration. All reactions were conducted at room temperature.

\section{Measurement and analysis}

The measurements were made using a $\mathrm{CO}_{2}$ isotope analyser (CCIA 36-EP, LGR, USA) exploiting the ICOS technique as described in ref. 13-15. Briefly, a high-finesse optical cavity consisting of two very high-reflectivity mirrors $(R \sim 99.98 \%)$ provides an optical path length of $\sim 3 \mathrm{~km}$ thereby increasing the sensitivity considerably. The high-resolution absorption spectra of the stable isotopes ${ }^{12} \mathrm{C}^{16} \mathrm{O}^{16} \mathrm{O}$ and ${ }^{13} \mathrm{C}^{16} \mathrm{O}^{16} \mathrm{O}$ were acquired by probing the ro-vibrational lines at the wavenumbers $4874.448 \mathrm{~cm}^{-1}$ and $4874.086 \mathrm{~cm}^{-1}$, respectively in the vibrational combination band of $\mathrm{CO}_{2}$ molecule and subsequently the concentrations of the isotopic species were reported in parts per million (ppm).

\section{Author contributions}

M. P. (Manik Pradhan) arranged the funding and supervised the whole study; M. P. (Manik Pradhan) and A. M. provided the conception of the study; S. M., M. P. (Mithun Pal) and A. M. designed the study; S. M., M. P. (Mithun Pal) and A. M. performed the experiments and analysed the data; all authors drafted the manuscript and critically reviewed.

\section{Conflict of interests}

The authors declare no conflict of interests.

\section{Acknowledgements}

The authors acknowledge the funding from the Technical Research Centre (TRC) (No. All1/64/SNB/2014(C)) of the S. N. Bose Centre, Kolkata for this work. S. Maithani, M. Pal and A. Maity acknowledge the Department of Science \& Technology (DST, India) for Inspire Fellowships.

\section{References}

1 N. E. Dixon, T. C. Gazzola, R. L. Blakeley and B. Zermer, J. Am. Chem. Soc., 1975, 97(14), 4131.

2 J. B. Sumner, J. Biol. Chem., 1926, 69, 435.

3 H. L. Mobley and R. P. Hausinger, Microbiol. Rev., 1989, 53(1), 85.

4 A. Maity, M. Pal, S. Maithani, B. Ghosh, S. Chaudhuri and M. Pradhan, J. Breath Res., 2016, $10(3), 036007$.

5 Y. Qin and J. M. S. Cabral, Appl. Biochem. Biotechnol., 1994, 49(3), 217.

6 A. Maity, M. Pal, S. Som, S. Maithani, S. Chaudhuri and M. Pradhan, Anal. Bioanal. Chem., 2017, 409, 193-200.

7 B. Krajewska, J. Mol. Catal. B: Enzym., 2009, 59(1), 9-21.

8 T. C. Huang and D. H. Chen, J. Chem. Technol. Biotechnol., 1991, 52(4), 433.

9 N. D. Jespersen, J. Am. Chem. Soc., 1975, 97(7), 1662.

10 B. R. van Eldik and M. Brindell, J. Biol. Inorg Chem., 2012, 17(7), 1123.

11 D. Walther, M. Ruben and S. Rau, Coord. Chem. Rev., 1999, 182, 67-100.

12 I.-S. Park and R. P. Hausinger, Science, 1995, 267(5201), 1156.

13 E. R. Crosson, K. N. Ricci, B. A. Richman, F. C. Chilese, T. G. Owano, R. A. Provencal, M. W. Todd, J. Glasser, A. A. Kachanov, B. A. Paldus, T. G. Spence and R. N. Zare, Anal. Chem., 2002, 74, 2003.

14 A. Maity, S. Som, C. Ghosh, G. Dutta Banik, S. B. Daschakraborty, S. Ghosh, S. Chaudhuri and M. Pradhan, J. Anal. At. Spectrom., 2014, 29, 2251.

15 A. Maity, G. D. Banik, C. Ghosh, S. Som, S. Chaudhuri, S. B. Daschakraborty, S. Ghosh, B. Ghosh, A. K. Raychaudhuri and M. Pradhan, J. Breath Res., 2014, 8(1), 016005. 